\title{
Estimating the annual risk of infection with Mycobacterium tuberculosis among adolescents in Western Kenya in preparation for TB vaccine trials
}

Videlis Nduba ${ }^{1,2^{*}}$, Anna H. van't Hoog ${ }^{2,3}$, Annefleur de Bruijn², Ellen M. H. Mitchell ${ }^{2,4}$, Kayla Laserson ${ }^{5}$ and Martien Borgdorff ${ }^{2}$

\begin{abstract}
Background: Adolescents are a prime target group for tuberculosis (TB) vaccine trials that include prevention of infection (POI). The BCG vaccine is given at birth and does not prevent TB infection. TB infection, a critical endpoint for $\mathrm{POI}$ vaccine trials would need to be documented to estimate sample sizes in target populations.

Methods: Adolescents aged 12-18 years of age were enrolled in an area under continuous demographic surveillance. A tuberculin skin test (TST) survey was conducted as part of a study on TB prevalence and incidence. All adolescents got TSTs at enrolment and returned after $72 \mathrm{~h}$ for reading. A TST of $\geq 10 \mathrm{~mm}$ if HIV negative or $\geq 5$ $\mathrm{mm}$ if HIV positive, was considered positive.

Results: Of 4808 adolescents returning for TST readings (96\% of those enrolled), mean age was 14.4 (SD 1.9), 4518(94\%) were enrolled in school and 21(0.4\%) gave a previous history of tuberculosis. Among adolescents with TST reactivity, the mean TST induration was $13.2 \mathrm{~mm}$ (SD 5.4). The overall prevalence of latent TB infection was 1544/4808 (32.1, 95\% Cl 29.2-35.1) with a corresponding annual risk of TB infection (ARTI) of $2.6 \%(95 \% \mathrm{Cl} 2.2-3.1)$. Risk factors for a positive TST included being male (OR 1.3, 95\% Cl 1.2,1.5), history of having a household TB contact (OR 1.5, 95\% Cl 1.2,1.8), having a BCG scar (OR 1.5,95\% Cl 1.2,1.8), living in a rural area (OR 1.4, 95\% Cl 1.1,1.9), and being out of school (OR 1.8, 95\% Cl 1.4,2.3).

Conclusion: We conclude that the high TB transmission rates we found in this study, suggest that adolescents in this region may be an appropriate target group for TB vaccine trials including TB vaccine trials aiming to prevent infection.
\end{abstract}

Keywords: ARTI, Tuberculosis, Adolescents, TST, Risk factors, TB vaccines

\section{Background}

Kenya ranks 10th out of 22 high TB burden countries globally [1]. The high prevalence of HIV in Kenya $[1,2]$ is a major contributing factor to TB incidence. Siaya County in Western Kenya has a high burden of tuberculosis and HIV

\footnotetext{
*Correspondence: vnduba@kemri.org; vnduba@gmail.com

The work presented in this paper was performed under the KEMRI and CDC Collaboration in western Kenya

${ }^{1}$ Kenya Medical Research Institute, Centre for Respiratory Diseases Research (CRDR), PO Box 47855-00100, Nairobi, Kenya

${ }^{2}$ Academic Medical Center of the University of Amsterdam, Amsterdam, The Netherlands

Full list of author information is available at the end of the article
}

with a TB case notification rate of 400/100,000 [3] and HIV prevalence of $15.1 \%$ [1].

Latent tuberculosis infection (LTBI) is the presence of Mycobacterium tuberculosis (MTB) in the body without signs and symptoms, or radiographic or bacteriologic evidence of tuberculosis (TB) disease [4]. One method to measure the trend of TB transmission is through repeated tuberculin surveys in order to estimate the trend of the prevalence of tuberculous infection and annual risk of tuberculous infection (ARTI). ARTI is used to measure the effectiveness of TB control programs. In addition, If TST conversion is a secondary endpoint for

(c) The Author(s). 2019 Open Access This article is distributed under the terms of the Creative Commons Attribution 4.0 International License (http://creativecommons.org/licenses/by/4.0/), which permits unrestricted use, distribution, and reproduction in any medium, provided you give appropriate credit to the original author(s) and the source, provide a link to the Creative Commons license, and indicate if changes were made. The Creative Commons Public Domain Dedication waiver (http://creativecommons.org/publicdomain/zero/1.0/) applies to the data made available in this article, unless otherwise stated. 
candidate vaccines preventing infection, ARTI estimates may also be used to inform the sample size of such trials.

Kenya has carried out several TST surveys to estimate the ARTI. These surveys were standardized by targeting primary school children aged 6-13 years and using the same TST technique [5-7]. The surveys were conducted in randomly selected districts and weighted for the underlying population distribution based on the most recent census. The ARTI estimates for Siaya district (where our present study was conducted) were $0.36,1.10$ and $1.45 \%$ for the surveys conducted in 1986-1990, 1994-1996 and 2004-2007 respectively with a mean age of 10 years in each sampled population indicating a rising ARTI over time [5-7].

Bacillus Calmette-Guerin (BCG), the TB vaccine given at birth, has not been shown to reliably prevent pulmonary tuberculosis in adolescents [8]. Adolescents may be prime candidates to receive new more effective $T B$ vaccines because they are entering an age of steeply rising TB rates [9]. TB vaccine trials enrolling adolescents will need to measure efficacy using several endpoints, including TB disease incidence. Measuring the ARTI and the prevalence of infection in preparation for TB vaccine trials can give an indication of TB transmission in target communities. In this study, we aimed to estimate the annual risk of infection with MTB among 12-18 year olds. Some of the interim results of this study have previously been reported in an abstract at the Biennial infectious disease conference, Nairobi Hospital Convention Centre, Nairobi, Kenya, 2017.

\section{Methods}

\section{Study design and sample size}

The study area, Karemo Division with a population of 85,000 people, part of Siaya County is under a continuous health and demographic surveillance system (HDSS) [10]. The HDSS collects biannual data using household surveys. In brief, the study area was divided into 17 clusters of approximately equal population size. The clusters were randomly selected to give each adolescent an equal probability of participation. Eight out of 17 clusters were used for enrolment. In each cluster, HDSS data was used to identify households with adolescents; parents at these households were then approached to have their children participate in the study. The survey was conducted as part of a study on TB prevalence and incidence which used a prospective observational cohort design enrolling adolescents aged $12-18$ years [11].

\section{Study procedures}

\section{Informed consent and clinical interviews}

Parental consent was obtained at home by study staff prior to inviting adolescents to a mobile field site where minor assent was obtained prior to study participation. During enrolment, standard social demographic data were collected including age, sex, school enrolment status, parental social economic status, parental mortality, recent migration, and urban or rural residence. In addition, several clinical characteristics were collected including history of immunization with BCG, history of tuberculosis, BCG scar (we used the presence of a scar to stratify BCG status), weight and height. Study procedures have been described in more detail elsewhere [11]. The study received ethical approval of the Kenya Medical Research Institute and the US Centres for Disease Control and Prevention.

\section{Tuberculin skin test and HIV testing}

All enrolled adolescents were offered a tuberculin skin test (TST) for LTBI after they provided a clinical history and vital signs were recorded. The TST used $0.1 \mathrm{ml}$ of tuberculin purified protein derivative (PPD) containing 5TU (tuberculin units) RT23 with Tween 80 (Statens Serum Institute, Copenhagen, Denmark) and was injected intradermally into the middle dorsal region of the right forearm using a disposable tuberculin syringe and G.26 needle. Adolescents were offered a TST after giving clinical history and getting vital signs recorded. Adolescents returned after $72 \mathrm{~h}$ for the reading of their TST results. Late TST readings were allowed up to a maximum of 7 days. All adolescents were offered HIV counselling and testing during the TST reading day. Parental/ guardian consent and adolescent assent were obtained prior to conducting HIV testing. Adolescents identified with HIV were referred to HIV care and treatment services at the Patient Support Centre at the Siaya District Hospital or to the nearest accessible Patient Support Centre.

The TST cut off we used as evidence for LTBI was $\geq 10 \mathrm{~mm}$ in adolescents that did not have HIV or whose HIV status was unknown and $\geq 5 \mathrm{~mm}$ in adolescents with HIV [12].

\section{Statistical analysis}

Statistical analysis was performed using SAS 9.2 (SAS Institute Inc., Cary, NC, US). A three point moving average was used on the TST induration data to look for digit preference by observing differences in peaks between actual and smoothed data. The point prevalence of LTBI and 95\% confidence intervals were calculated using survey procedures in SAS and adjusted for clustering. The prevalence of LTBI was estimated using the cut-off method and mirror method [13]. The cut-off method used the study defined cut-off of $10 \mathrm{~mm}$. In the mirror method, the mode of the distribution of those with presumed tuberculous infection is derived from the overall frequency distribution of TST reactions among 
the adolescents. Then, the total number of adolescents with positive TST reactions was estimated as the sum of the number of adolescents showing reaction sizes equal to the mode and double the number of adolescents with reaction sizes larger than the mode [13]. Bivariate analysis was used to determine significant associations between various risk factors and a positive tuberculin skin test. Factors significant at the $p<0.2$ level were further explored in a multivariate model using logistic regression. ARTI was calculated with the formula ARTI $=1-(1 \text {-prevalence of infection })^{1 / \text { mean age }}[14]$.

\section{Results}

A total of 5004 adolescents aged $12-18$ years were enrolled between August 2008 and August 2009 (Fig. 1). All adolescents enrolled received tuberculin skin tests (TST) and a total of $4808(96.0 \%)$ came for their TST readings and were included in the analysis. There was no difference in socio demographic factors between adolescents dropping after enrolment and before TST readings and those that continued the study. Of the 4808 with TST readings, the mean age was 14.4 (SD 1.9), 2327 (48\%) were female, the mean body mass index (BMI) was 17.9 (SD 2.5), 4518 (94\%) were currently enrolled in school, 4550 (95\%) lived in a rural area, 1289
(26.8\%) were orphaned, 861 (18\%) had no BCG scar, $23(0.5 \%)$ were HIV positive, and $21(0.4 \%)$ gave a history of previous tuberculosis (Table 1). There was no significant difference in the baseline characteristics between those who came back for TST readings and those that failed to turn up [data not shown].

\section{TST indurations}

Of the 4808 adolescents with TST results, 4166 (86.7\%) were read within 4 days, 2762 (58\%) did not have any induration. Of the 3947 adolescents with a BCG scar, 2177 (55\%) had no induration compared to 585/861 (86\%) of adolescents without a BCG scar. Among adolescents with TST reactivity, the mean TST induration was 13.2 $\mathrm{mm}$ (SD 5.4). There was marked digit preference at 10 $\mathrm{mm}, 15$ and $16 \mathrm{~mm}$ and some digit avoidance at $13 \mathrm{~mm}$ (Fig. 2). The smoothed data (three-point moving average) of all the adolescents showed a mode of 17 (Fig. 2). Smoothed data for adolescents with and without a BCG scar showed a mode of 17 and 18 respectively (Fig. 2).

\section{Prevalence of infection and ARTI}

Using the cut-off method, including one adolescent with HIV with a TST of $5 \mathrm{~mm}$, the overall prevalence of LTBI was $1544 / 4808$ (32.1, 95\% CI 29.2-35.1) with

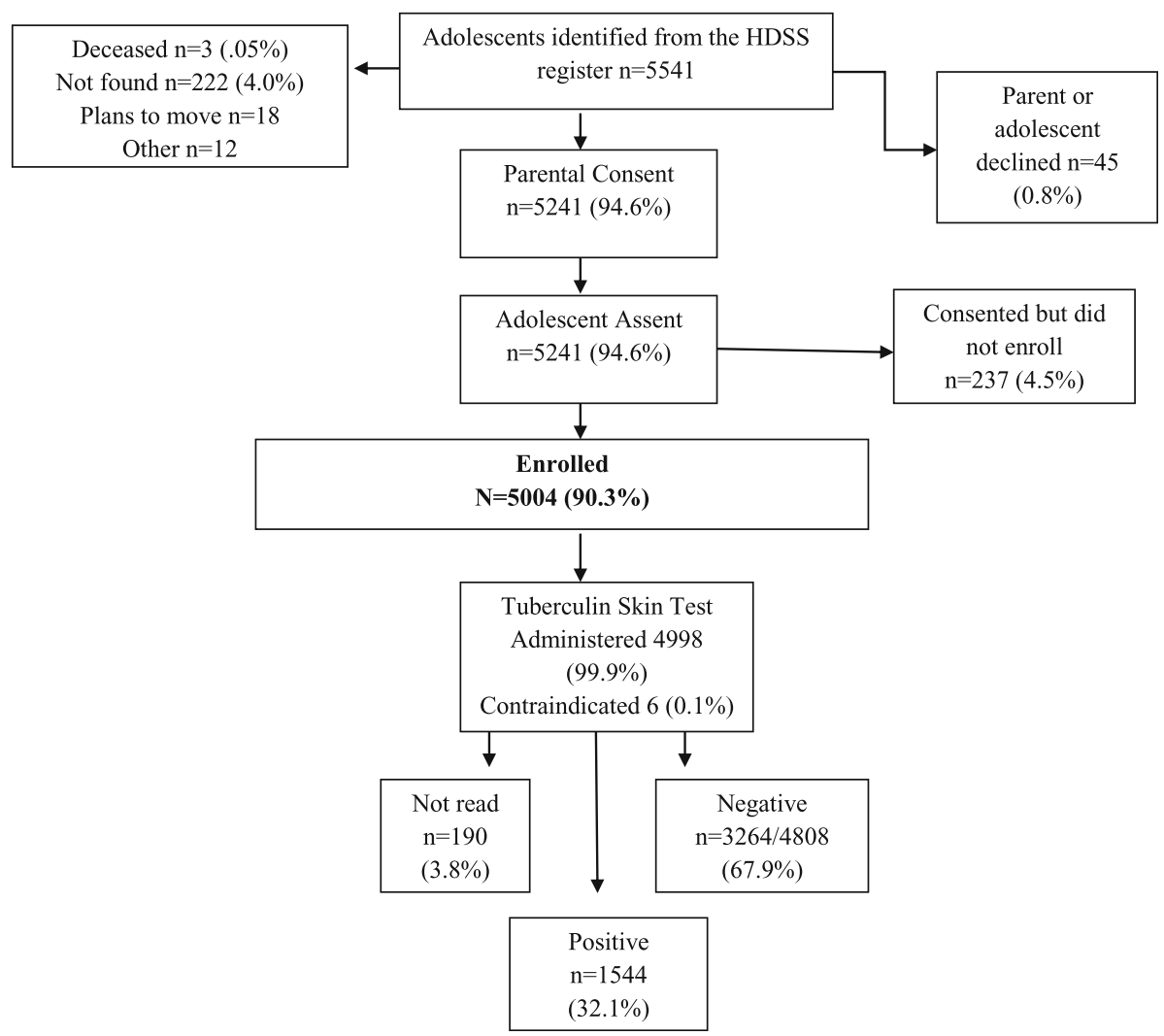

Fig. 1 Participant enrolment and tuberculosis skin testing 
Table 1 Demographic characteristics of 4808 adolescents undergoing tuberculin skin testing in Kenya, 2008-2009

\begin{tabular}{|c|c|c|}
\hline Characteristic & Category & All (4808) \\
\hline \multirow[t]{2}{*}{ Tuberculin skin test (TST) } & Reactive & $1544(32.1 \%)$ \\
\hline & Non reactive & $3264(67.9 \%)$ \\
\hline \multirow[t]{2}{*}{ Sex } & Female & $2327(48.4 \%)$ \\
\hline & Male & $2481(51.6 \%)$ \\
\hline \multirow[t]{2}{*}{ School going } & Yes & $4518(94.0 \%)$ \\
\hline & No & $290(6.0 \%)$ \\
\hline \multirow[t]{3}{*}{ HIV status } & Positive & $23(0.5 \%)$ \\
\hline & Negative & $1985(41.3 \%)$ \\
\hline & Unknown & $2165(45.0 \%)$ \\
\hline \multirow[t]{2}{*}{ Residence } & Rural & $4550(94.6 \%)$ \\
\hline & Urban & $258(5.4 \% \%)$ \\
\hline \multirow[t]{2}{*}{ Previous TB } & Yes & $21(0.4 \%)$ \\
\hline & No & $4787(99.6 \%)$ \\
\hline \multirow[t]{2}{*}{ History of TB contact } & Yes & $138(2.9 \%)$ \\
\hline & No & $4670(97.1 \%)$ \\
\hline \multirow[t]{2}{*}{ Deceased parents } & One parent deceased or both alive & $3519(73.2 \%)$ \\
\hline & Both deceased & $1289(26.8 \%)$ \\
\hline \multirow[t]{3}{*}{ Socio economic status } & Upper class & $1582(32.9 \%)$ \\
\hline & Middle class & $1636(34.0 \%)$ \\
\hline & Lower class & 1590 (33.1\%) \\
\hline
\end{tabular}

a corresponding ARTI of $2.6 \%$ (95\% CI 2.2-3.1). Among adolescents with a BCG scar, the prevalence of positive reactions was $33.5 \%$ (95\% CI 30.3-36.8) with an estimated ARTI of $2.7 \%$ (95\% CI 2.2-3.2) and among adolescents without a BCG scar, the prevalence of positive reactions was $25.6 \%$ (95\% CI 22.0-29.2) and the corresponding ARTI 2.1\% (95\% CI 1.1-3.1) (Table 2). The Mirror method suggested an ARTI of 2.2\% (95\% CI 1.72.7) in those with and $2.1 \%$ (95\% CI 1.1-3.1) for those without a BCG scar.
Risk factors for tuberculous infection (LTBI)

Using the cut-off method, risk factors for a positive TST result were being male (OR 1.3, 95\% CI 1.2,1.5), history of having a household TB contact (OR 1.5, 95\% CI 1.2, 1.8), having a BCG scar (OR 1.5,95\% CI 1.2,1.7) living in a rural area (OR 1.4, 95\% CI 1.1,1.9), and being out of school (OR 1.8,1.4,2.3). The mirror method identified being male (OR 1.4, 95\% CI 1.2,1.7) and having a household TB contact (OR 1.6, 95\% CI 1.2,2.1) as risk factors for a positive TST (Table 3 ).

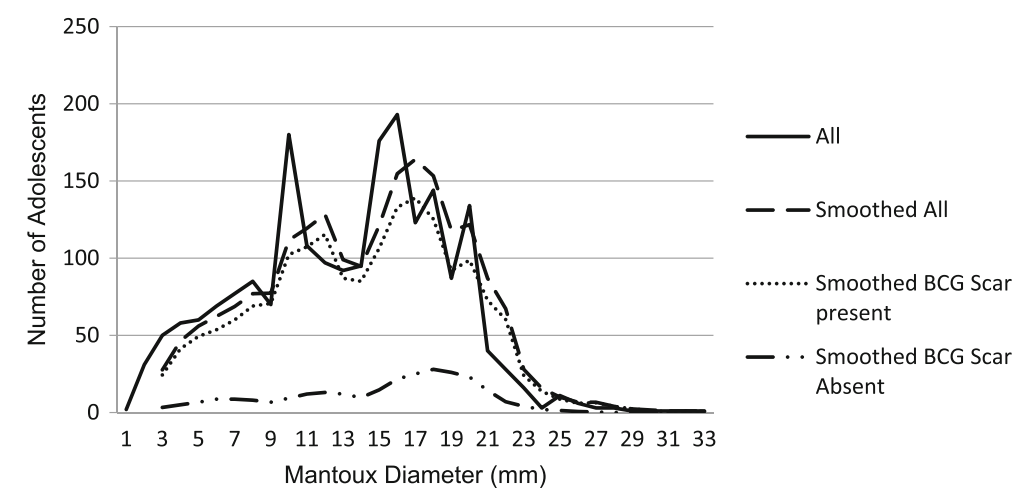

Fig. 2 A three point moving average of TST indurations for all adolescents with and without a BCG scar.*BCG scar present 2177/3947(55.2\%) had $0 \mathrm{~mm}$ induration. *BCG scar absent 585/861 (86\%) had $0 \mathrm{~mm}$ induration 
Table 2 ARTI estimates and prevalence of infection presented for all adolescents, those with and without a BCG scar

\begin{tabular}{|c|c|c|c|c|c|c|c|c|}
\hline \multirow[t]{2}{*}{ 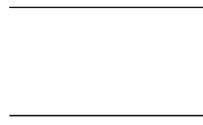 } & \multirow[t]{2}{*}{ N } & \multirow{2}{*}{$\begin{array}{l}\text { Mean } \\
\text { age } \\
\text { (years) }\end{array}$} & \multicolumn{3}{|c|}{$\geq 10 \mathrm{~mm}^{\mathrm{b}}$} & \multicolumn{3}{|c|}{ Mirror method $17 \mathrm{~mm}^{\mathrm{a}}$} \\
\hline & & & $P$ & ARTI & $\mathrm{Cl}(95 \%)$ & $\bar{P}$ & $A R T I^{C}$ & $\mathrm{Cl}(95 \%)$ \\
\hline All & 4808 & 14.4 & $32.1 \%$ & $2.6 \%$ & $(2.2,3.1)$ & $27.6 \%$ & $2.2 \%$ & $(1.8,2.6)$ \\
\hline BCG scar & 3947 & 14.4 & $33.5 \%$ & $2.7 \%$ & $(2.2,3.2)$ & $27.8 \%$ & $2.2 \%$ & $(1.7,2.7)$ \\
\hline BCG scar absent & 859 & 14.2 & $25.6 \%$ & $2.1 \%$ & $(1.1,3.1)$ & $27.0 \%$ & $2.1 \%$ & $(1.1,3.1)$ \\
\hline
\end{tabular}

Cl 95\% Confidence interval

${ }^{a}$ The total number of adolescents with true reactions was calculated by adding the number of adolescents showing reaction sizes equal to the mode to double the number with reaction sizes larger than the mode to determine the numerator

${ }^{\mathrm{b}}$ The Cut-off for HIV+ was $\geq 5 \mathrm{~mm}$

${ }^{\mathrm{C}} \mathrm{ARTI}$ formula $=1-\left(1\right.$-prevalence of infection) ${ }^{1 / \text { mean age }}$

All risk factors identified during bivariate analysis remained independently associated with a positive TST in multivariate analysis (Table 3).

\section{Discussion}

Our study showed an ARTI of 2.6\% (95\% CI 2.23.1 ) with the cut-off method and $2.2 \%$ (95\% CI $1.8-$ 2.6) with the mirror method, both of which are more than double the expected based on serial TST surveys among children aged 10 years in the same area that reported an ARTI of $1.1 \%$ [5-7]. This suggests that TB transmission may be more intense among adolescents than among young children. This is consistent with findings by Dodd et al. who suggested estimates of TB infection based on surveys in children may underestimate infection incidence in adults [15]. A higher risk of infection among adolescents than among children of primary school age has also been reported elsewhere [16, 17]. In addition, a golden age has previously been described where the incidence of infection goes down after 5 years of age and begins to rise in adolescence [18].

Table 3 Risk factors for a positive tuberculin skin test (TST) for the $10 \mathrm{~mm}$ cut-off method and the 17 mm mirror method

\begin{tabular}{|c|c|c|c|c|c|c|c|c|c|}
\hline \multirow[t]{2}{*}{ Risk Factor } & & \multicolumn{3}{|c|}{$\begin{array}{l}\text { Tuberculin skin test }>=10 \mathrm{~mm} n= \\
4808\end{array}$} & \multirow{2}{*}{$\begin{array}{l}\text { Multivariate } \\
\text { OR, 95\% Cl }\end{array}$} & \multicolumn{3}{|c|}{$\begin{array}{l}\text { Tuberculin skin test }>=17 \mathrm{~mm} \mathrm{n}= \\
4808\end{array}$} & \multirow{2}{*}{$\begin{array}{l}\text { Multivariate } \\
\text { OR, } 95 \% \mathrm{Cl}\end{array}$} \\
\hline & & Negative & Positive & $\begin{array}{l}\mathrm{OR}, 95 \% \\
\mathrm{Cl}\end{array}$ & & Negative & Positive & $\begin{array}{l}\mathrm{OR}, 95 \% \\
\mathrm{Cl}\end{array}$ & \\
\hline \multirow[t]{2}{*}{ Sex } & Female & 1650 & $\begin{array}{l}677 / 2327 \\
(29.1 \%)\end{array}$ & 1 & & 2076 & $\begin{array}{l}251 / 2327 \\
(10.8 \%)\end{array}$ & 1 & \\
\hline & Male & 1614 & $\begin{array}{l}867 / 2481 \\
(34.9 \%)\end{array}$ & $\begin{array}{l}1.3(1.2 \\
1.5)\end{array}$ & $1.3(1.2,1.5)$ & 2129 & $\begin{array}{l}352 / 2481 \\
(14.2 \%)\end{array}$ & $\begin{array}{l}1.4(1.2 \\
1.6)\end{array}$ & $1.4(1.2,1.7)$ \\
\hline \multirow[t]{2}{*}{$\begin{array}{l}\text { History of a house hold TB } \\
\text { contact }\end{array}$} & Yes & 224 & $150 / 374(40.1 \%)$ & $\begin{array}{l}1.5(1.2, \\
1.8)\end{array}$ & $1.5(1.2,1.8)$ & 119 & 19/138 (13.8\%) & 1 & \\
\hline & No & 3040 & $\begin{array}{l}1394 / 4434 \\
(31.4 \%)\end{array}$ & 1 & & 4086 & $\begin{array}{l}584 / 4670 \\
(12.5 \%)\end{array}$ & $\begin{array}{l}1.6(1.2 \\
2.1)\end{array}$ & $1.6(1.2,2.1)$ \\
\hline \multirow[t]{2}{*}{ Previous TB } & Yes & 15 & $6 / 21(28.6 \%)$ & 1 & & 18 & $3 / 21(14.3 \%)$ & 1 & \\
\hline & No & 3232 & $\begin{array}{l}1528 / 4787 \\
(32.1 \%)\end{array}$ & $\begin{array}{l}0.8(0.3, \\
2.1)\end{array}$ & & 4163 & $\begin{array}{l}597 / 4760 \\
(12.5 \%)\end{array}$ & $\begin{array}{l}1.2(0.4 \\
3.7)\end{array}$ & \\
\hline \multirow[t]{2}{*}{ BCG Scar } & Yes & 2623 & $\begin{array}{l}1324 / 3947 \\
(33.5 \%)\end{array}$ & $\begin{array}{l}1.3(1.2 \\
1.7)\end{array}$ & $1.5(1.3,1.8)$ & 3450 & $\begin{array}{l}497 / 3947 \\
(12.6 \%)\end{array}$ & $\begin{array}{l}1.0(0.8 \\
1.3)\end{array}$ & $1.0(0.8,1.3)$ \\
\hline & No & 641 & $220 / 861(25.6 \%)$ & 1 & & 753 & $106 / 859$ (12.3\%) & 1 & \\
\hline \multirow[t]{2}{*}{ Residence } & Urban & 189 & $69 / 258(26.7 \%)$ & 1 & & 231 & $27 / 258(10.5 \%)$ & 1 & \\
\hline & Rural & 3075 & $\begin{array}{l}1475 / 4550 \\
(32.4 \%)\end{array}$ & $\begin{array}{l}1.2(1.0 \\
1.5)\end{array}$ & $1.4(1.1,1.9)$ & 3974 & $\begin{array}{l}576 / 4550 \\
(12.7 \%)\end{array}$ & $\begin{array}{l}1.2(0.8 \\
1.9)\end{array}$ & $1.2(0.8,1.9)$ \\
\hline \multirow[t]{2}{*}{ School going } & Yes & 3103 & $\begin{array}{l}1415 / 4518 \\
(31.3 \%)\end{array}$ & 1 & & 3960 & $\begin{array}{l}558 / 4518 \\
(12.4 \%)\end{array}$ & 1 & \\
\hline & No & 161 & $129 / 290(44.5 \%)$ & $1.8(1.4,2.2)$ & $1.8(1.4,2.3)$ & 245 & $45 / 290(15.5 \%)$ & $\begin{array}{l}1.3(0.9 \\
1.8)\end{array}$ & $1.3(1.0,1.8)$ \\
\hline \multirow[t]{2}{*}{ Orphaned } & Yes & 1136 & $\begin{array}{l}585 / 1721 \\
(34.0 \%)\end{array}$ & 1 & & 1474 & $\begin{array}{l}247 / 1721 \\
(14.4 \%)\end{array}$ & 1 & \\
\hline & No & 2128 & $\begin{array}{l}959 / 3087 \\
(31.1 \%)\end{array}$ & $\begin{array}{l}1.1(1.0 \\
1.3)\end{array}$ & $1.1(1.0,1.3)$ & 2731 & $\begin{array}{l}356 / 3087 \\
(11.5 \%)\end{array}$ & $\begin{array}{l}1.3(1.1 \\
1.5)\end{array}$ & $1.3(1.1,1.5)$ \\
\hline
\end{tabular}


There are methodological challenges to measuring ARTI in adolescents, including the influence of previous BCG vaccination and exposure to environmental mycobacteria on TST results $[19,20]$. Even though TST is a relatively inexpensive test, it has low specificity causing false positives in patients with history of BCG vaccination and environmental mycobacteria exposure [21]. In this study, BCG vaccination status was indeed associated with a positive TST result in the cut-off method, but the mirror method appeared to have eliminated this bias. ARTI was high both in those with and without a BCG scar, using either the cut-off or mirror method. Exposure to environmental mycobacteria appears not to have been a major factor given the low frequency of intermediate reactions $(5-9 \mathrm{~mm})$ and the similar prevalence estimate using the cut-off method and mirror method in those without BCG vaccination scar. Even though an interferon gamma release assay (IGRA) was not performed to ascertain TB infection, excellent concordance between tuberculin skin test and IGRA conversion rates has been previously demonstrated [22].

Risk factors for a positive TST were similar to those reported in studies elsewhere, including male sex [9] and having a BCG scar [23]. The higher risk of TB infection in males might be related to older boys having more contact with adult men among whom TB prevalence is higher, as suggested by Dodd [15]. Although only a small proportion $(6 \%)$ of adolescents in this study were not currently enrolled in school, they were significantly more likely to have a positive TST compared to in school youth 45 and 31\% respectively (OR 1.8, 95\% CI 1.1, 2.9). However, this subgroup may be a good target population for intensified case finding and prevention. The majority of adolescents enrolled were of rural residence (94.6\%) and this was associated with a positive TST also in a multivariate model. However, the difference was not large (32\% versus 27\%). As expected history of a household contact was strongly predictive of a positive TST $40.1 \%$ versus $31.4 \%$ ). Previous TB surprisingly was not associated with a positive TST, but numbers were small. Having both parents deceased was associated with a positive TST (34\% versus $31 \%)$ ). The study area has a high HIV prevalence of $15.1 \%$ [2] and many deaths among parents are likely to have been due to HIV/AIDS, which in this area is strongly associated with tuberculosis indicating a higher risk of LTBI in orphaned children before their parents died.

The ARTI estimates are derived from a point prevalence estimate and repeated TST surveys would need to be conducted to see how this correlates with the incidence of infection and age associated risks of infection [16, 17]. While BCG had some influence on TST reading results using the cut-off method, this was no longer the case using the mirror method. Digit preference was corrected by smoothing, though might be further reduced in the future by further strengthening training and supervision.

Preventing TB disease instead of infection has been the key goal of vaccine development [24]. Epidemiological and mathematical modelling studies have shown a pre-infection vaccine would have a high level impact on TB disease control [24]. A pre-infection vaccine will require choice of an age range where the risk of infection rises but before majority of the age group becomes infected. Adolescents are an important group for vaccination against TB because while TB incidence is relatively low in the age group 5-14 years, it rises rapidly in adolescence [25]. In our study majority of adolescents $(67.9 \%)$ were TST negative indicating this would be a good age group to target for prevention of infection vaccine studies. We have reported on the incidence of tuberculosis in adolescents elsewhere [26]. The incidence of TB addresses the sample sizes needed for TB vaccine efficacy trials preventing disease; whether primary disease or reactivation from previous TB infection. Because of difficulties in having a human challenge model with tuberculosis, a pathway to understanding the immune mechanisms of protection against tuberculosis with new vaccines would be to conduct prevention of infection with M.tuberculosis studies as a marker of biologic impact [24]. The studies will need to take into account the huge burden of non tuberculous mycobacteria (NTM) infection in this population including using interferon gamma release assays to disciminate M.TB infection from NTM infection [11]. Since infection with M.tuberculosis happens much more often than TB disease, the trials will be much smaller and trial results would be obtained much sooner allowing a read-out on a TB vaccine candidate's likely efficacy before doing larger scale efficacy studies.

\section{Conclusion}

We conclude that the high TB transmission rates we found in this study, suggest that adolescents in schools in this region may be an appropriate target group for TB vaccine trials including $\mathrm{TB}$ vaccine trials aiming to prevent infection. Out of school adolescents might be harder to enroll and follow up for TB incidence.

\section{Additional file}

Additional file 1: Annual risk of TB infection (ARTI). The data set provides all the variables that were used for analysis of the results in this manuscript. (CSV $1400 \mathrm{~kb}$ )

\section{Abbreviations}

ARTI: Annual Risk of tuberculous infection; BCG: Bacille Calmette-Guerin; HDSS: Health and demographic surveillance system; HIV: Human immunodeficiency virus; LTBI: Latent tuberculosis infection;

MTB: Mycobacterium tuberculosis; POI: Prevention of infection; PPD: Purified protein derivative; TB: Tuberculosis; TST: Tuberculin skin test; TU: Tuberculin units 


\section{Acknowledgements}

We would like to acknowledge the Director KEMRI for approval of this manuscript and KEMRI/CDC. KEMRI/CDC is a member of the INDEPTH Network. We also acknowledge the dedicated staff especially recruitment staff and village reporters that made it possible to contact all potential study participants. Some of the interim results of this study have previously been reported in an abstract at the Biennial infectious disease conference, Nairobi Hospital Convention Centre, Nairobi, Kenya, 2017.

\section{Disclaimer}

The findings and conclusions in this report are those of the authors and do not necessarily represent the official position of the Centers for Disease Control and Prevention.

\section{Authors' contributions}

VN wrote the protocol, conducted the study, analysed and interpreted the data and wrote the manuscript. AB participated in data analysis and manuscript development. $\mathrm{AH}, \mathrm{EM}, \mathrm{KL}$ and $\mathrm{MB}$ participated in developing the protocol, reviewed data and multiple versions of the manuscript. All authors read and approved the final manuscript.

\section{Funding}

This study was supported by grants from: The European and Developing Countries Clinical Trials Partnership (grant number: IP_07_32080_003), Aeras Global TB Vaccine Foundation, KNCV TB Foundation, Netherlands Organisation for Scientific Research (NACCAP), Vienna School of Clinical Research, San Rafaele Laboratory, Milan Italy. The funding agencies had no role in the design of the study and collection, analysis, and interpretation of data and in writing the manuscript.

\section{Availability of data and materials}

The data supporting the findings of this study have been included as an additional supporting file in the submission (Additional file 1).

\section{Ethics approval and consent to participate}

The protocol and informed consent forms were reviewed and approved by the Kenya Medical Research Institute (KEMRI) local and national scientific steering committees and the KEMRI national ethical review committee (SSC 1295) and the Institutional Review Boards (IRBs) of CDC and the AERAS Global TB Vaccine Foundation. Written informed parental consent was obtained from all parents/guardians at home by study staff prior to inviting adolescents to a mobile field site where minor assent was obtained prior to study participation.

\section{Consent for publication}

Not applicable

\section{Competing interests}

KNCV tuberculosis foundation provided some funding for the project and participated in Manuscript preparation. The other funding agencies did not participate in data analysis or the preparation of this manuscript or in the decision to submit the manuscript for publication. The authors have no conflicts of interest relevant to this article to disclose.

\author{
Author details \\ ${ }^{1}$ Kenya Medical Research Institute, Centre for Respiratory Diseases Research \\ (CRDR), PO Box 47855-00100, Nairobi, Kenya. ${ }^{2}$ Academic Medical Center of \\ the University of Amsterdam, Amsterdam, The Netherlands. ${ }^{3}$ Amsterdam \\ Institute for Global Health \& Development, University of Amsterdam, \\ Amsterdam, The Netherlands. ${ }^{4}$ International Institute of Social Studies (ISS), \\ Erasmus University Rotterdam, Rotterdam, The Netherlands. ${ }^{5}$ Bill \& Melinda \\ Gates foundation, Seattle, USA. \\ Received: 19 April 2019 Accepted: 24 July 2019 \\ Published online: 02 August 2019

\section{References} \\ 1. NACC. Kenya AIDS indicator survey (KAIS), National AIDS Control Council. \\ 2012. https:/naccorke/wp-content/uploads/2015/10/KAIS-2012pdf. \\ 2. Statistics KNBO. Kenya Demographic And Heath Survey 2008-2009. 2010.
}

3. NLTP. Kenya national leprosy and tuberculosis program report, Nationa Leprosy and Tuberculosis Control Program. 2009. https://www.nltpcoke/ annual-reports/.

4. CDC. Latent tuberculosis infection: a guide for primary health care providers. 2013. https://www.cdc.gov/tb/publications/ttbi/pdf/targetedltbi.pdf.

5. Odhiambo JA, Borgdorff MW, Kiambih FM, et al. Tuberculosis and the HIV epidemic: increasing annual risk of tuberculous infection in Kenya, 19861996. Am J Public Health. Jul 1999;89(7):1078-82.

6. Kwamanga D, Chakaya J, Sitienei J, Kalisvaart N, L'Herminez R, van der Werf MJ. Tuberculosis transmission in Kenya: results of the third National Tuberculin Survey. Int J Tuberc Lung Dis. 2010;14(6):695-700.

7. Bosman MC, Swai OB, Kwamanga DO, Agwanda R, Idukitta G, Misljenovic O. National tuberculin survey of Kenya, 1986-1990. Int J Tuberc Lung Dis. 1998;2(4):272-80.

8. Colditz GA, Brewer TF, Berkey CS, et al. Efficacy of BCG vaccine in the prevention of tuberculosis Meta-analysis of the published literature. JAMA. Mar 2 1994;271(9): 698-702.

9. Mahomed H, Hawkridge T, Verver S, Geiter L, Hatherill M, Abrahams DA, et al. Predictive factors for latent tuberculosis infection among adolescents in a high-burden area in South Africa. Int J Tuberc Lung Dis. 2011;15(3):331-6.

10. Odhiambo FO, Laserson KF, Sewe M, Hamel MJ, Feikin DR, Adazu K, et al. Profile: the KEMRI/CDC Health and Demographic Surveillance System-Western Kenya. Int J Epidemiol. 2012;41(4):977-87.

11. Nduba V, Hoog AH, Mitchell E, Onyango P, Laserson K, Borgdorff M. Prevalence of tuberculosis in adolescents, western Kenya: implications for control programs. Int J Infect Dis. 2015:35:11-7.

12. (CDC) CfDCaP. Targeted Tuberculin Testing and Treatment of Latent Tuberculosis Infection. MMWR Morb Mortal Wkly Rep. 2000;49(RR-6) Retrieved from http://www.cdc.gov/mmwr/PDF/rr/rr4906.pdf.

13. Rieder $\mathrm{HL}$. Methodological issues in the estimation of the tuberculosis problem from tuberculin surveys. Tuber Lung Dis. 1995;76(2):114-21.

14. Adetifa IM, Muhammad AK, Jeffries D, Donkor S, Borgdorff MW, Corrah T, et al. A Tuberculin Skin Test Survey and the Annual Risk of Mycobacterium tuberculosis Infection in Gambian School Children. PLoS One. 2015;10(10): e0139354.

15. Dodd PJ, Looker C, Plumb ID, Bond V, Schaap A, Shanaube K, et al. Ageand Sex-Specific Social Contact Patterns and Incidence of Mycobacterium tuberculosis Infection. Am J Epidemiol. 2016;183(2):156-66.

16. Sutherland I, Fayers PM. The association of the risk of tuberculous infection with age. Bull Int Union Tuberc. 1975;50(1):70-81.

17. Nagelkerke N, Heisterkamp S, Borgdorff M, Broekmans J, Van Houwelingen H. Semi-parametric estimation of age-time specific infection incidence from serial prevalence data. Stat Med. 1999;18(3):307-20.

18. Basu Roy R, Whittaker E, Seddon JA, Kampmann B. Tuberculosis susceptibility and protection in children. Lancet Infect Dis. 2019;19(3):e96-e108.

19. Rieder H. Annual risk of infection with Mycobacterium tuberculosis. Eur Respir J. 2005;25(1):181-5.

20. Fine PE, Ponnighaus JM, Maine $\mathrm{N}$. The distribution and implications of BCG scars in northern Malawi. Bull World Health Organ. 1989;67(1):35-42.

21. Chapman HJ, Lauzardo M. Advances in diagnosis and treatment of latent tuberculosis infection. J Am Board Fam Med. 2014;27(5):704-12.

22. Andrews JR, Hatherill M, Mahomed $H$, et al. The dynamics of QuantiFERONTB gold in-tube conversion and reversion in a cohort of south African adolescents. Am J Respir Crit Care Med. Mar 1 2015;191(5):584-91.

23. Farhat M, Greenaway C, Pai M, Menzies D. False-positive tuberculin skin tests: what is the absolute effect of BCG and non-tuberculous mycobacteria? Int J Tuberc Lung Dis. 2006:10(11):1192-204.

24. Hawn TR, Day TA, Scriba TJ, et al. Tuberculosis vaccines and prevention of infection. Microbiol Mol Biol Rev. Dec 2014:78(4):650-71.

25. Marais BJ, Donald PR, Gie RP, Schaaf HS, Beyers N. Diversity of disease in childhood pulmonary tuberculosis. Ann Trop Paediatr. 2005:25(2):79-86.

26. Nduba V, Van't Hoog AH, Mitchell EMH, Borgdorff M, Laserson KF. Incidence of active tuberculosis and cohort retention among adolescents in Western Kenya. Pediatr Infect Dis J. 2018;37(1):10-5.

\section{Publisher's Note}

Springer Nature remains neutral with regard to jurisdictional claims in published maps and institutional affiliations. 